\title{
Reversible Downregulation of Protein Kinase A during Olfactory Learning Using Antisense Technique Impairs Long-Term Memory Formation in the Honeybee, Apis mellifera
}

\author{
André Fiala, Uli Müller, and Randolf Menzel \\ Institut für Neurobiologie der Freien Universität Berlin, 14195 Berlin, Germany
}

In this study, we examined the role of cAMP-dependent protein kinase (PKA) in associative olfactory learning of the honeybee, Apis mellifera. In the bee, specific interference with molecules to clarify their role in a certain behavior is difficult, because genetic approaches, such as mutants or transgenic animals, are not feasible at the moment. As a new approach in insects in vivo, we report the use of short antisense oligonucleotides. We show that phosphorothioate-modified oligodeoxynucleotides complementary to the mRNA of a catalytic subunit of PKA directly injected into the bee brain cause a reversible and specific downregulation of both the amount of the catalytic subunit and of PKA activity by $10-15 \%$. The amounts of the regulatory subunit of PKA, as well as PKC, are not affected. The slight "knockdown" of PKA activity during the training proce-

Decades of research on the mechanisms underlying learning and memory have led to the current concept of changes in synaptic connections as the neural substrate of experience-dependent behavioral plasticity (Milner et al., 1998). Within this concept, phosphorylation processes mediated by protein kinases are believed to be a central molecular mechanism in the machinery transducing specific external stimuli into synaptic changes (Walaas and Greengard, 1991). Investigations on a couple of model systems, including mollusks, insects, and mammals, revealed a role for cAMP-dependent protein kinase (PKA) in processes of experience-dependent plasticity. PKA is a heterodimeric enzyme consisting of two regulatory (R) and two catalytic (C) subunits. As a response to $\mathrm{cAMP}$, the $\mathrm{C}$ subunits are released and thereby activated (Taylor et al., 1990). In the marine snail Aplysia calfornica, PKA is involved in the synaptic facilitation underlying behavioral plasticity of a defensive reflex (for review, see Byrne et al., 1993; Abel and Kandel, 1998). In the fruit fly Drosophila melanogaster, a variety of mutants or transgenic animals defective in molecular components of the cAMP-PKA pathway reveal impairments in learning and memory formation (for review, see Davis, 1996; Dubnau and Tully, 1998). In vertebrates, a transgenic mouse overexpressing a $\mathrm{R}$ subunit of PKA has offered a successful model for demonstrating a connection between PKA

\footnotetext{
Received March 24, 1999; revised Sept. 3, 1999; accepted Sept. 3, 1999.

This work was supported by the Deutsche Forschungsgemeinschaft (Sonderforschungsbereich 515/C5). We are grateful to Dr. Daniel Kalderon for providing the anti-DC0 antibody, Dr. Lore Grünbaum for providing the anti-PKC antibody, and Mary Wurm for help with this manuscript. We also are grateful to the anonymous reviewers who helped to improve this manuscript substantially.

Correspondence should be addressed to André Fiala, Institut für Neurobiologie der Freien Universität Berlin, Königin-Luise-Strasse 28-30, 14195 Berlin, Germany. E-mail: fiala@zedat.fu-berlin.de.

Copyright (C) 1999 Society for Neuroscience 0270-6474/99/1910125-10\$05.00/0
}

dure, a classical olfactory conditioning of the proboscis extension reflex, neither affects acquisition nor memory retention 3 or $6 \mathrm{hr}$ after training. However, it causes an impairment of longterm memory retention $24 \mathrm{hr}$ after training. Downregulation of PKA $3 \mathrm{hr}$ after training has no detectable effect on memory formation. We conclude that PKA contributes to the induction of a long-term memory $24 \mathrm{hr}$ after training when activated during learning. Second, we demonstrate that the antisense technique is feasible in honeybees in vivo and provides a new and powerful tool for the study of the molecular basis of learning and memory formation in insects.

Key words: antisense oligonucleotides; Apis mellifera; cAMPdependent protein kinase; honeybee; insect; long-term memory; olfactory learning; PKA

activity, hippocampal synaptic long-term potentiation (LTP), and hippocampus-based memory (Abel et al., 1997).

The honeybee Apis mellifera provides an unique model system to investigate mechanisms of learning and memory on different levels, from complex behaviors to molecular correlates, in an integrative way (for review, see Menzel and Müller 1996). Under laboratory conditions, a proboscis extension reflex (PER) can be conditioned by pairing an odor as the conditioned stimulus (CS) with a sucrose reward as the unconditioned stimulus (US) (Kuwabara, 1957; Bitterman et al., 1983). Neuronal pathways mediating CS and US are at least partially known, and cellular correlates of learning and memory have been identified (Hammer and Menzel, 1995; Hammer, 1997). However, on the molecular level, all insects pale compared with Drosophila, with its sophisticated genetic approaches. Pharmacological approaches are difficult in insects because drugs are usually characterized for vertebrates, and target specificity in insects often remains unclear. In this report, however, we demonstrate that the use of phosphorothioatemodified oligodeoxynucleotides (S-ODNs) with a specific antisense sequence, a well-established method in several vertebrate systems (for review, see Ogawa and Pfaff, 1998), provides a powerful tool for investigating the function of distinct proteins in associative learning in honeybees. Although reports of PKA activity kinetics altered by olfactory conditioning suggest a role of PKA for learning and memory in the bee also (Eisenhardt et al., 1997; Grünbaum and Müller, 1997), a causal demonstration is still lacking. By injecting antisense S-ODNs complementary to the mRNA sequence of a catalytic subunit (C subunit) directly into the bee brain, we are able to reversibly decrease the amount of the $\mathrm{C}$ subunit and to detect effects on learning and memory. Here, we report that long-term memory $1 \mathrm{~d}$ after training is impaired by a slight downregulation of PKA activity during learning. 


\section{MATERIALS AND METHODS}

General animal treatment. Honeybee workers (Apis mellifera carnica) were caught in the afternoon at the hive entrance, immobilized by chilling, and harnessed into metal tubes by strips of tape between their heads and thoraces. Bees were fed with $10 \mu$ l of sucrose solution $(1.25 \mathrm{M})$ and kept in a dark, humid container until the experiment started the next day. During the experimental procedure, bees were fed with $10 \mu \mathrm{l}$ of sucrose solution $(1.25 \mathrm{M})$ in the morning and in the evening. All experiments were performed at room temperature $\left(20-25^{\circ} \mathrm{C}\right)$.

Classical olfactory conditioning paradigm. Olfactory conditioning of the PER consisted of the temporal forward pairing of an odor as the CS with sucrose solution as the US. Twenty seconds before each conditioning trial, i.e., CS-US pairing, bees were placed in the experimental situation in front of an exhauster and blown on with an air stream delivered from an aquarium pump through a syringe $\sim 1 \mathrm{~cm}$ distant from the bee's antennae. The CS was delivered by a valve shunting the air stream for 5 sec through a $1 \mathrm{ml}$ syringe loaded with a piece of filter paper soaked with $20 \mu \mathrm{l}$ of carnation oil. Two seconds after the onset of the CS, the US was applied by touching both antennae with a toothpick moistened with sucrose solution $(1.25 \mathrm{M})$ for $1 \mathrm{sec}$. Bees were then allowed to lick the toothpick for an additional $4 \mathrm{sec}$. In the conditioning procedure, three conditioning trials were presented with an intertrial interval of 2 min 20 sec. In the memory retention procedure, only the CS was delivered for 5 $\mathrm{sec}$, after $20 \mathrm{sec}$ placement in front of the exhauster. Results are presented as the percentage of honeybees showing proboscis extension. In the case of acquisition, proboscis extension was recorded during the $2 \mathrm{sec}$ of CS presentation without US, and in the case of memory retention, proboscis extension was recorded during the $5 \mathrm{sec}$ of the CS presentation. To test multiple, differently treated groups of animals for overall differences in acquisition or memory retention, the total number of proboscis extension responses of every animal during the whole test period was recorded, and the data was analyzed using the KruskalWallis test. In the case of significance, pairwise comparisons were performed using the Mann-Whitney $U$ test to reveal which group is different from which other one. Significantly different groups were tested daywise using the $\chi^{2}$ test.

Injection of oligonucleotides. S-ODNs (18 mer) with or without the $5^{\prime}$ end biotin label were purchased from Roth (Karlsruhe, Germany). In preliminary screening experiments, four antisense sequences were tested with the following sequences: (1) 5'-CGCGGCATTGTTGCCCAT-3', complementary to the nucleotides +1 to +18 , of the PKA (catalytic subunit) mRNA sequence (Rosenboom et al., 1996), at which +1 refers to the first nucleotide of the start codon; (2) 5'-CGCTAATACGATTTGTGC-3', complementary to the nucleotides +451 to +468 ; (3) $5^{\prime}$ GGCGCGAGATATTCTGGC-3', complementary to the nucleotides +612 to +629 ; and (4) the antisense sequence $5^{\prime}$-GCAGTCGCGGCATTGTTG-3', complementary to the nucleotides +6 to +23 . The sequences were chosen with regard to a balanced $\mathrm{AT} / \mathrm{CG}$ ratio, the lack of hairpins or repetitive elements and $\mathrm{C} / \mathrm{G}$ nucleotides at the ends. The control S-ODN sequence, further designated as the scrambled S-ODN sequence, was 5'-CTGCGTGGAGGCATTCGT-3', containing the same nucleotides as the used antisense sequence number 4 but in a randomized order. S-ODNs were dissolved in sterile buffer solution, further designated as solvent, containing $10 \mathrm{~mm}$ HEPES-NaOH, pH 6.7, $130 \mathrm{~mm} \mathrm{NaCl}, 6 \mathrm{~mm} \mathrm{KCl}, 4$ $\mathrm{mm} \mathrm{MgCl}_{2}, 5 \mathrm{~mm} \mathrm{CaCl}_{2}, 25 \mathrm{~mm}$ glucose, and $0.16 \mathrm{M}$ sucrose, calibrated to $500 \mathrm{mOsm}$, and stored at $-16^{\circ} \mathrm{C}$ as stock solution. A tiny hole was pricked into the cornea of the median ocellus with a small cannula to allow the insertion of a fine glass capillary filled with the S-ODN solution $\sim 200 \mu \mathrm{m}$ into the brain. Solution $(200 \mathrm{nl})$ with a final S-ODN concentration of $250 \mu \mathrm{M}$ was injected into the brain along the median ocellar tract using an air pressure injector (General Valve, Fairfield, NJ).

Histological determination of S-ODN uptake and distribution. To remove the bees' brains, the heads were cut off and quickly mounted on wax. The brain was carefully removed using a scalpel. Brains of animals injected with $5^{\prime}$ end biotin-labeled S-ODNs (antisense or scrambled control sequence) or those of untreated animals were prepared and fixed in $4 \%$ formaldehyde dissolved in PBS containing $137 \mathrm{~mm} \mathrm{NaCl}, 2.7 \mathrm{~mm}$ $\mathrm{KCl}, 10 \mathrm{mM} \mathrm{Na}_{2} \mathrm{HPO}_{4}$, and $1.7 \mathrm{mM} \mathrm{KH}_{2} \mathrm{PO}_{4}$, for 2-3 hr on ice. The tissue was washed for $5 \mathrm{~min}$ in PBS, dehydrated in increasing grades of ethanol and, finally incubated in xylene for $1 \mathrm{~min}$. Subsequently, the brains were incubated in paraplast (Sigma, Deisenhofen, Germany) at $60^{\circ} \mathrm{C}$ overnight and embedded in it by chilling on ice. Sections, $10-\mu \mathrm{m}$-thick, were cut and mounted on poly-D-lysine-coated slides. After rehydrating the sections in xylene and decreasing grades of ethanol, the slides were washed with PBS containing $0.1 \%$ Triton X-100 (PBS-Tx). The sections were blocked against nonspecific binding and treated with avidin-coupled peroxidase, using the reagents and following the instructions of the Elite ABC Standard kit from Vectastain (Vector Laboratories, Burlingame, CA). The staining reaction was performed using $0.2 \mathrm{mg} / \mathrm{ml}$ diaminobenzidine (Sigma) dissolved in PBS-Tx as the substrate. After terminating the staining reaction with $50 \%$ ethanol and dehydration by incubating the slides in increasing ethanol grades, and, finally in xylene, the sections were fixed with Entellan (Merck, Darmstadt, Germany). The stained sections were recorded using an Olympus Opticals (Hamburg, Germany) DC 10 camera, and the contrast of the digital picture was slightly enhanced using the PhotoShop program (Adobe, version 5.0; Adobe Systems, San Jose, CA).

Immunohistochemical detection of PKA C subunit. Bee brains were prepared, and sections were made as described above. After blocking the sections with blocking solution containing PBS-Tx and $0.5 \%$ bovine serum albumin (BSA) (Serva, Heidelberg, Germany) for $1 \mathrm{hr}$, the polyclonal anti-DC0 immunoglobulin (IgG), provided by Dr. D. Kalderon (Columbia University, New York, NY), diluted 1:3000 in the blocking solution, was applied to the sections and incubated overnight at $4^{\circ} \mathrm{C}$. The sections were washed (three times for $10 \mathrm{~min}$ each) in PBS-Tx and incubated for $2 \mathrm{hr}$ with biotinylated anti-rabbit $\mathrm{IgG}$ diluted 1:5000 in blocking solution. After washing (three times for $10 \mathrm{~min}$ each), the slides were incubated with avidin-coupled alkaline phosphatase diluted 1:5000 in blocking solution for $1 \mathrm{hr}$ at room temperature. The staining reaction was performed by incubating the sections in $0.1 \mathrm{~m}$ Tris-HCl, $\mathrm{pH} 8.8$, containing $0.1 \mathrm{M} \mathrm{NaCl}, 1 \mathrm{~mm} \mathrm{MgCl} 2,1 \mathrm{mg}$ of 5-bromo-4-chloro-3-indolyl phosphate (AppliChem, Darmstadt, Germany), and $0.5 \mathrm{mg}$ of nitro blue tetrazolium (Sigma). After terminating the staining reaction, sections were dehydrated and fixed as described above.

Western blot. Bee brains were prepared as described above, and thoraces and abdomen were simply dissected with a scalpel after cutting off legs and wings. Heads of Drosophila melanogaster were cut off under a microscope after freezing the flies in liquid nitrogen. Each prepared tissue was homogenated on ice in PBS with added $1 \mathrm{~mm}$ EDTA and $1 \mathrm{~mm}$ EGTA. Protein amounts of the homogenates were quantified using the method described by Bradford (1976). Each homogenate $(20 \mu \mathrm{l} ; 4-5 \mu \mathrm{g}$ of protein) mixed with $5 \mu \mathrm{l}$ of SDS sample buffer $(0.5 \mathrm{M}$ Tris-HCl, $\mathrm{pH} 6.8$, containing 5\% SDS, 5\% 2-mercaptoethanol, and $20 \%$ glycerol) was subjected to SDS-PAGE and blotted on a nitrocellulose filter. The prestained SDS molecular weight standard mixture from Sigma was used to determine molecular weights. After blocking the filter against nonspecific binding in $0.5 \%$ BSA dissolved in PBS, the filter was incubated with the anti-DC0 IgG, diluted 1:3000 in PBS with $0.5 \%$ BSA overnight at $4{ }^{\circ} \mathrm{C}$. The filter was washed (three times for $10 \mathrm{~min}$ each in PBS) and incubated with alkaline phosphatase-coupled anti-rabbit IgG, diluted 1:5000 in PBS containing $0.5 \% \mathrm{BSA}$, for $2 \mathrm{hr}$. After washing (three times for $10 \mathrm{~min}$ each in PBS), the filter was incubated in $20 \mathrm{ml}$ of $0.1 \mathrm{M}$ Tris- $\mathrm{HCl}, \mathrm{pH} 8.8$, containing $0.1 \mathrm{M} \mathrm{NaCl}, 1 \mathrm{~mm} \mathrm{MgCl}, 1 \mathrm{mg}$ 5-bromo-4-chloro-3-indolyl phosphate, and $0.5 \mathrm{mg}$ of nitro blue tetrazolium. After terminating the staining reaction, the filter was dried.

Quantitative determination of protein amounts by ELISA. Bee heads were cut off, quickly mounted on wax, and opened to expose the brain. The optical lobes and the ocelli were cut off with a scalpel, and the remaining central brain, including protocerebrum, subesophageal ganglion, and antennal lobes, was subsequently placed into $500 \mu \mathrm{l}$ of ice-cold buffer containing $50 \mathrm{~mm}$ Tris-HCl, pH 6.8, $10 \mathrm{~mm}$ 2-mercaptoethanol, 1 mM EDTA, and 1 mM EGTA. After homogenizing the tissue on ice, the samples were frozen in liquid nitrogen until the next day. After thawing, the samples were bound to high-bond plates (Greiner, Frickenhausen, Germany) and diluted within each row of wells to a dilution range from $1 / 100$ to $1 / 3200$ of one central brain. After the antigen bound to the wells (1.5 $\mathrm{hr}$ at $4^{\circ} \mathrm{C}$ ), the remaining binding sites were blocked by incubation with $0.5 \%$ BSA diluted in PBS for $2 \mathrm{hr}$. Subsequently, the wells were incubated with the primary antibodies, diluted in $0.5 \%$ BSA in PBS overnight at $4^{\circ} \mathrm{C}$. We used the anti-DC0 $\operatorname{IgG}$ (see above), an antibody raised against PKA regulatory subunit type II, described by Müller (1997), or an antibody against PKC, described by Grünbaum and Müller (1998). After washing (three times for 10 min each with PBS), the wells were incubated with the appropriate biotinylated secondary antibody (anti-mouse or anti-rabbit IgG) diluted 1:5000 in PBS with $0.5 \%$ BSA for $2 \mathrm{hr}$ at room temperature. Plates were washed (three times for $10 \mathrm{~min}$ each with PBS) and incubated with avidin-coupled alkaline phosphatase diluted 1:5000 in PBS with $0.5 \%$ BSA for $1 \mathrm{hr}$. After washing (three times for $10 \mathrm{~min}$ each with PBS) $100 \mu \mathrm{l}$ of the substrate solution containing $0.1 \mathrm{M}$ Tris$\mathrm{HCl}, \mathrm{pH} 8.8,1 \mathrm{~mm} \mathrm{MgCl}_{2}$, and $1 \mathrm{~mm} o$-nitrophenylphosphate (Sigma) 
was added to each well. To quantify the amount of antigen, the substrate conversion by the phosphatase was measured with an ELISA reader (SLT 400 ATX; SLT Labinstruments, Gailsheim, Germany) at $405 \mathrm{~nm}$ versus $620 \mathrm{~nm}$ background. The optical density values of the dilutions ranging from $1 / 100$ to $1 / 3200$ of one brain resulted in a linear function whose slope reflected the amounts of antigen. Because only measurements performed on the same ELISA plate can be directly compared and only relative protein amounts are detectable using that method, 16 central brain homogenates were measured on one plate with four groups (antisense S-ODN-injected, scrambled S-ODN-injected, solvent-injected, and untreated bees; $n=4$ each). The slopes measured on each plate were normalized to the mean value of the measurements of the four untreated brains, resulting in a mean value of $1 \pm$ SEM for the four untreated brains in relation to the treated brains. Seven to nine ELISA plates were measured per experiment, and the normalized values were pooled. To test for differences between the four groups, the Kruskal-Wallis test was applied. In the case of significance, the Mann-Whitney $U$ test was used for pairwise comparisons.

In vitro PKA phosphorylation assay. The PKA activity was determined using phosphatase inhibitor 1 (I1), purified from bovine brain, as the specific substrate (Hildebrandt and Müller, 1995a). Bee brains were prepared as described above and homogenized in ice-cold buffer containing $50 \mathrm{~mm}$ Tris-HCl, pH 7.7, $10 \mathrm{~mm}$ 2-mercaptoethanol, $1 \mathrm{~mm}$ EDTA, and 1 mm EGTA. Kinase activity was measured by incubating 10 $\mu \mathrm{l}$ of each sample with $5 \mu \mathrm{l}$ of phosphorylation buffer containing a final concentration of $50 \mathrm{~mm}$ Tris- $\mathrm{HCl}, \mathrm{pH} 7.7,10 \mathrm{~mm}$ 2-mercaptoethanol, 1 mM EDTA, 1 mм EGTA, $10 \mathrm{~mm} \mathrm{MgCl}_{2}, 10 \%$ I1, $5 \mu \mathrm{M}$ ATP, $5 \mu \mathrm{M}$ 8-bromo-cAMP (8-Br-cAMP), and $1 \mu \mathrm{Ci}\left[\gamma^{-32} \mathrm{P}\right] \mathrm{ATP}(5000 \mathrm{Ci} / \mathrm{mmol}$; NEN Life Science Products, Brussels, Belgium) for $15 \mathrm{sec}$. The phosphorylation reaction was stopped with $5 \mu \mathrm{l}$ of SDS sample buffer. Samples were subjected to SDS-PAGE and ${ }^{32} \mathrm{P}$ labeling was visualized by exposing the gels to Kodak X-Omat AR films (Eastman Kodak, Rochester, NY) for $2 \mathrm{~d}$. Films were scanned with a UMAX UC840 scanner (UMAX, Willich, Germany), and ${ }^{32} \mathrm{P}$ incorporation was quantified using the NIH Image program by measuring the intensity of the I1 bands. Antisense S-ODN- and scrambled S-ODN-injected bees were tested on each SDS gel. All values of each gel were related to the mean value of the scrambled S-ODN-injected bees. The difference between antisense S-ODN-treated bees and scrambled S-ODN-treated bees was tested for significance using the Mann-Whitney $U$ test.

\section{RESULTS}

\section{Pilot experiments on S-ODN concentrations and sequences}

Because the use of antisense S-ODNs in an insect has not been described before, we had to perform pilot experiments to adjust the technique to behavioral experiments with bees. First, we had to find out the appropriate S-ODN concentration for the injection into the bee brain. A large amount of fluid (200 nl) was chosen with the consideration that diff usion inside the brain should be as widespread as possible. S-ODN concentrations of various sequences were tested in parallel $(0.1-4 \mathrm{~mm})$, and the survival rate was observed. It turned out that $250 \mu \mathrm{M}$ represents the maximum concentration that does not affect survival rate or the elicitability of the proboscis extension reflex over a period of $4 \mathrm{~d}$ after injection, an important prerequisite for behavioral experiments. Higher concentrations lead to an increase in morbidity rate $(4 \%$ with $0.5 \mathrm{~mm}, 20 \%$ with $1 \mathrm{~mm}, 36 \%$ with $2 \mathrm{~mm}$, and $65 \%$ with $4 \mathrm{~mm}$; $n=70-78$ each) $6 \mathrm{hr}$ after injection. A single injection was performed rather than multiple or continuous injections to keep the time window of an antisense S-ODN-dependent downregulation in PKA $\mathrm{C}$ subunit as short as possible. Because not all antisense S-ODNs might be equally effective in their action on the target mRNA and because it is difficult to predict the affinity of antisense S-ODNs to their target mRNA in vivo, preliminary screening experiments on sequences were performed in a trialand-error manner. Four antisense S-ODNs were analyzed for their ability to affect the amount of PKA C subunit at various time points after the injection. Sequence numbers 3 and 4 (see
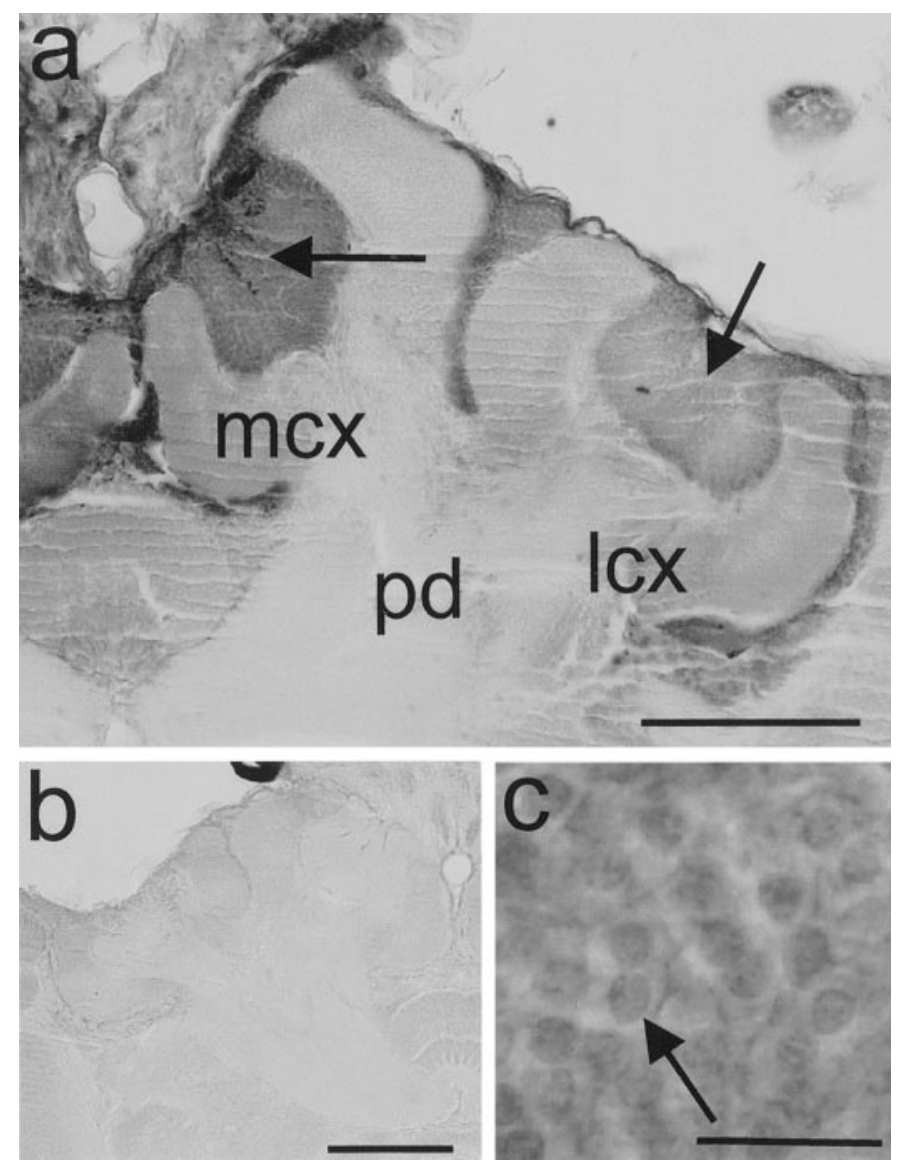

Figure 1. Detection of biotin-labeled S-ODNs $1 \mathrm{hr}$ after injection into the bee brain on a frontal section. S-ODNs are visible as dark staining, predominantly in somata regions, as the picture of one mushroom body (a) demonstrates. The Kenyon cell somata (arrows) are separated from the neuropils of the lateral $(l c x)$ and median calyx $(m c x)$ or the pedunculus $(p d)$ and stained conspicuously darker. Scale bar, $200 \mu \mathrm{m}$. The mushroom body from an untreated brain $(b)$ demonstrates the low background staining as a control. Scale bar, $200 \mu \mathrm{m}$. When focusing on somata of Kenyon cells with a higher magnification $(c)$, an accumulation in the cell nuclei becomes visible (arrow). Scale bar, $20 \mu \mathrm{m}$.

Material and Methods) caused a downregulation in the amount of PKA C subunit at $6 \mathrm{hr}$ after injection. Sequence number 4 was further analyzed using a scrambled S-ODN sequence as a control (see below).

\section{Distribution and cellular uptake of S-ODNs injected into the honeybee brain}

To reveal whether S-ODNs are taken up by bee neurons and to where they diffuse, biotin-labeled S-ODNs injected via the median ocellus were detected in brain sections $1 \mathrm{hr}$ after injection. The strongest staining, revealing the highest concentration of S-ODNs, is localized near the injection site, i.e., in the median ocellar tract, the upper part of the central complex, and in the somata region of the median calyces of the mushroom bodies. The staining intensity decreases from these central parts to the more peripheral parts of the brain, suggesting that a diffusion gradient results from the application technique. S-ODNs in a lower concentration can be observed in the lateral calyces of the mushroom bodies, the somata of the antennal lobes, and the somata of the subesophageal ganglion. Figure $1 a$ shows the median and the lateral calyx of one mushroom body, making it clearly visible that S-ODNs are predominantly taken up by cell 
somata. A darker staining of cell nuclei, suggesting an accumulation of S-ODNs in nuclei, can often be observed (Fig. 1c). No difference in distribution and cellular uptake between injected antisense S-ODNs or scrambled S-ODNs was observed. As a control for background staining, brains from untreated bees were processed identically and do not reveal a comparable strong staining (Fig. 1b).

\section{Histological distribution of PKA C subunit in the bee brain}

In this investigation, we used specific antisense S-ODNs complementary to an isoform of PKA C subunit, cloned and sequenced by Rosenboom et al. (1996), which is the homolog to the Drosophila C subunit isoform DC0. The high degree of sequence homology $(>90 \%)$ between the DC0 from Drosophila and the honeybee $\mathrm{C}$ subunit allows the use of a polyclonal antiserum, raised against Drosophila PKA (DC0 isoform) and kindly provided by Dr. D. Kalderon, to detect $\mathrm{C}$ subunit in the bee brain. Comparative immunoblotting of bee brain homogenate and Drosophila head homogenate shows that the $40 \mathrm{kDa}$ band reflecting DC0 in Drosophila also appears in the bee (Fig. 2a). Obviously, the antiserum against Drosophila DC0 is also specific for the honeybee $\mathrm{C}$ subunit. PKA C subunit is preferentially expressed in the nervous tissue, because homogenates of thoracal and abdominal tissue of equal protein amounts (4-5 $\mu \mathrm{g} / \mathrm{lane})$ do not reveal any detectable signal in contrast to the brain tissue (Fig. $2 b$ ). The histological distribution of PKA C subunit (Fig. 2c) reveals a conspicuously darker staining of the mushroom bodies compared with antennal lobes and protocerebrum. Interestingly, the antennal lobe neuropil shows clear immunoreactivity, whereas staining in the somata regions flanking the antennal lobe neuropil is barely detectable. The optical neuropils also show distinct and strong staining patterns, especially in cells surrounding the lamina, medulla, and lobula.

\section{Reversible and specific downregulation of the amount of PKA $C$ subunit and PKA activity}

Time course, degree, and specificity of a PKA C subunit downregulating effect of antisense $\mathrm{S}-\mathrm{ODN}$ injections were investigated by quantifying amounts of PKA C subunit in the bee brain. The optical lobes, which are not involved in olfactory associative learning and memory, were cut off and not considered. Using the ELISA technique with the antibody against PKA $\mathrm{C}$ subunit, the relative amount of this protein in the central brain was determined at various time points after injecting antisense S-ODNs compared with the control groups, namely scrambled S-ODNinjected, solvent-injected, and untreated brains. The amounts of PKA C subunit of solvent, antisense S-ODN-injected, and scrambled S-ODN-injected brains are normalized to the mean values of those from untreated animals.

Three hours after injection, no significant difference between the four groups could be detected ( $p>0.4$; df $=3 ; H=2.45$; Kruskal-Wallis test) (Fig. $3 a$ ). However, $6 \mathrm{hr}$ after injection, significant differences occur between the four groups $(p<0.05$; $\mathrm{df}=3 ; \mathrm{H}=13.47$; Kruskal-Wallis test) (Fig. $3 b$ ), which can be attributed to a reduction in PKA $\mathrm{C}$ subunit by $10-15 \%$ in the antisense S-ODN-treated group, because pairwise comparisons reveal significant differences from the scrambled S-ODN-injected group ( $p<0.05$; df $=1 ; U=313$; Mann-Whitney $U$ test), the solvent-injected group ( $p<0.05$; df $=1$; $U=328$; MannWhitney $U$ test), and the untreated group ( $p<0.05$; $\mathrm{df}=1 ; U=$ 208; Man-Whitney $U$ test), but no differences between the un-
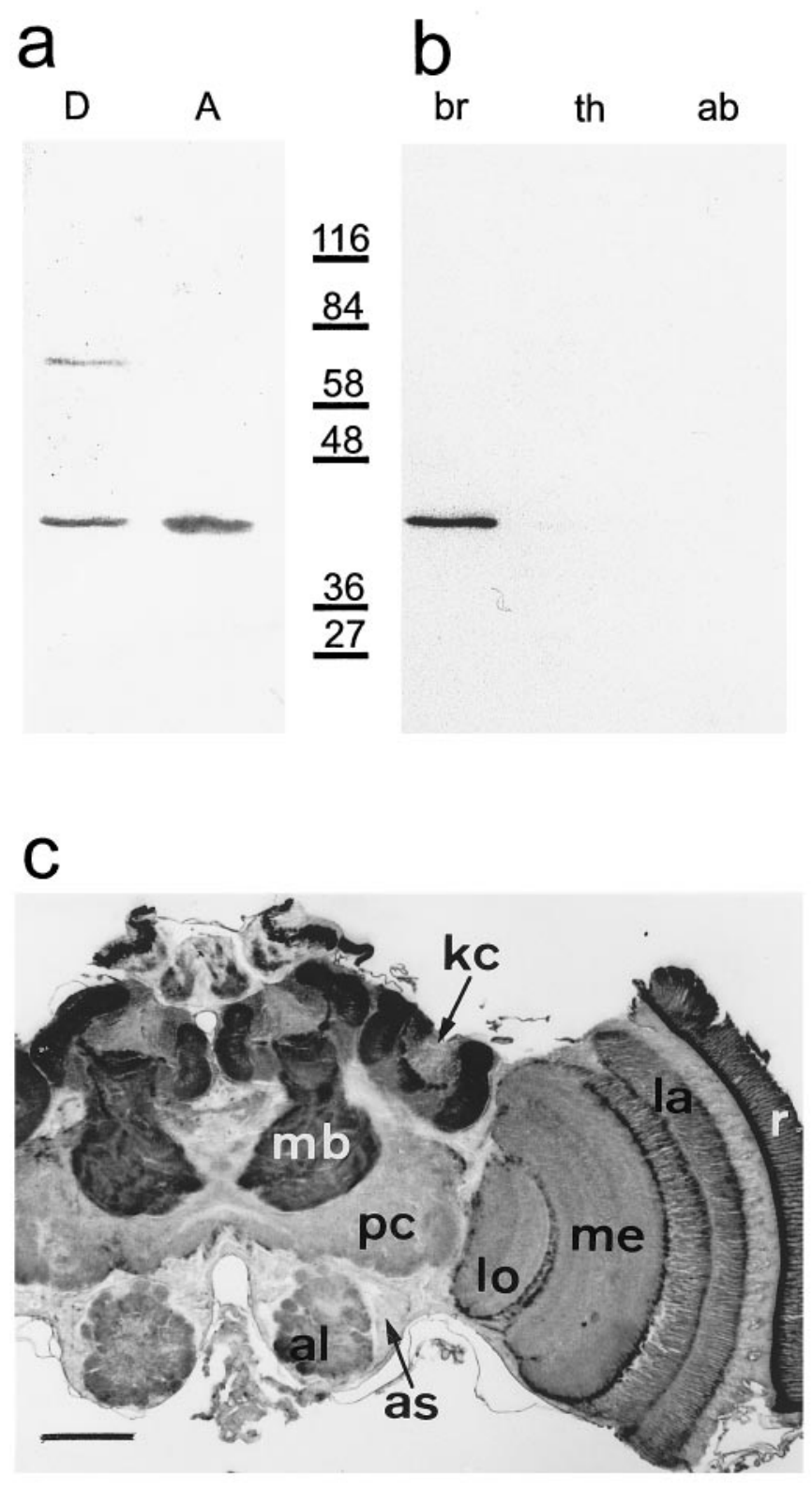

Figure 2. Immunological detection of PKA C subunit using an anti-DC0 antibody. An immunoblot (a) showing the DC0 isoform of PKA in Drosophila melanogaster head homogenate $(D)$ with a band at $40 \mathrm{kDa}$ and the corresponding PKA C subunit in brain homogenate of Apis mellifera $(A)$, also at $40 \mathrm{kDa}$. A second immunoblot $(b)$ compares bee brain homogenate $(b r)$, bee thorax homogenate $(t h)$, and bee abdomen homogenate $(a b)$ of equal protein amounts $(4-5 \mu \mathrm{g})$. At these protein amounts, PKA C subunit is detectable only in brain tissue. Molecular weights in kilodaltons for $a$ and $b$ is indicated by the numbers between the two blots. Immunostaining of a frontal section of the bee brain $(c)$ reveals a strong staining of the mushroom body neuropil $(\mathrm{mb})$ and the Kenyon cell somata $(k c)$. The protocerebrum $(p c)$ and antennal lobe neuropil $(a l)$ are stained considerably more weakly, and immunoreactivity is barely detectable in antennal lobe somata (as). The neuropils of the optical lobe, lobula (lo), medulla (me), and lamina (la) also reveal distinct staining patterns. The retina $(r)$ is dark because of its photopigments. Scale bar, $200 \mu \mathrm{m}$.

treated, solvent-injected, or scrambled S-ODN-injected group ( $p>0.3$; df $=1$; Mann-Whitney $U$ test). This downregulating effect of antisense-S-ODNs is reversible, as demonstrated by the fact that, $24 \mathrm{hr}$ after injection, no significant difference between 

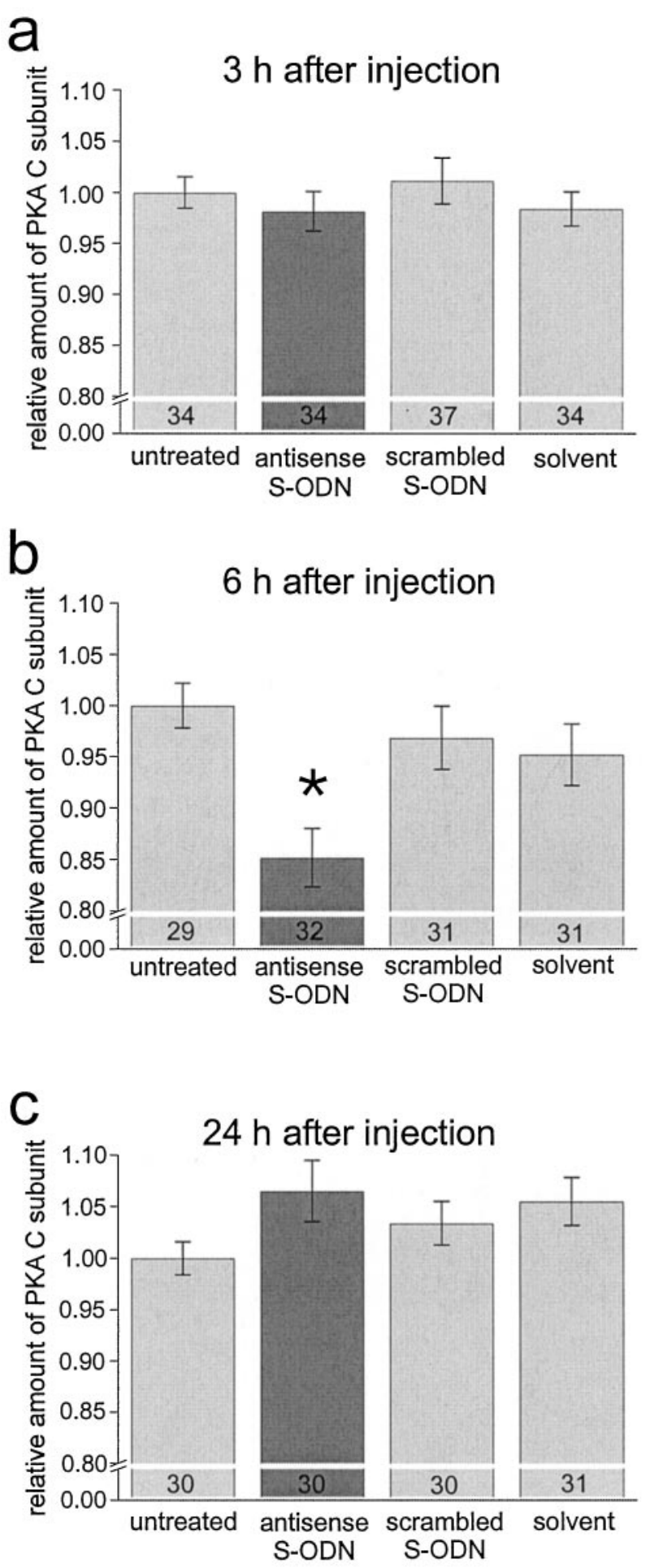

Figure 3. Quantification of PKA C subunit in bee brains without optical lobes. The amounts of PKA C subunit were measured $3(a), 6(b)$, or 24 (c) hr after injection of antisense S-ODNs, scrambled S-ODNs, or solvent relative to untreated animals using ELISA technique. Each column represents mean \pm SEM values of $n$ measurements as indicated by the numbers on the bars. As indicated by the asterisk, only the antisense-SODN-injected animals show a significant reduction in the amount of PKA and only at $6 \mathrm{hr}$ after injection ( $p<0.05$; Mann-Whitney $U$ test). the four groups could be detected any longer $(p>0.3 ; H=3.59$; Kruskal-Wallis test) (Fig. 3c).

To test whether the downregulating effect of antisense S-ODNs is specific to PKA C subunit, the relative amounts of PKA R subunit type II and PKC were also quantified using specific antibodies, which were described by Müller (1997) and Grünbaum and Müller (1998), respectively. No significant differences between the four groups could be detected, in the amounts of either PKA R subunit type II or PKC 3, 6, or $24 \mathrm{hr}$ after injection (Table 1). The measurements demonstrate, first, that the injection itself and the injection of scrambled S-ODNs do not produce any effect on the three investigated proteins. Second, a slight downregulation of the PKA C subunit by treatment with antisense-SODNs is specific to the target protein. Third, the onset of an effect of antisense S-ODNs on PKA C subunit is detectable between 3 and $6 \mathrm{hr}$ after injection and is reversible within $24 \mathrm{hr}$. However, it cannot be excluded that PKA is affected at time points between 6 and $24 \mathrm{hr}$ after injection.

Because the amount of PKA R subunit type II is not affected by antisense treatment (unlike the amount of PKA $\mathrm{C}$ subunit), a decrease in PKA activity caused by antisense treatment $6 \mathrm{hr}$ after injection seems probable. This assumption was checked by measuring PKA activity using a phosphorylation assay. Because no differences in the amounts of PKA C subunit were detected between untreated, solvent-injected, and scrambled S-ODNinjected bees, only antisense S-ODN-injected and scrambled $\mathrm{S}-\mathrm{ODN}$-injected bees were tested. In the presence of $5 \mu \mathrm{M} 8-\mathrm{Br}-$ cAMP, i.e., at a maximal activation of PKA, the antisensetreated bees reveal decreased PKA activity $(p<0.05$; df $=1$; $U=188$; Mann-Whitney $U$ test) (Fig. 4).

\section{Downregulation of the amount of PKA C subunit during training affects long-term memory}

The reversibility of the antisense effect allows us to decrease PKA activity during the learning process and to investigate memory retention at time points when the antisense effect has already vanished. In a first series of experiments, bees were trained $6 \mathrm{hr}$ after the injection of antisense S-ODNs $(n=147)$ and scrambled S-ODNs $(n=133)$, respectively, i.e., at a time point when a biochemical effect of antisense S-ODNs is apparent. To detect possible nonspecific effects of S-ODNs, a group of solventinjected animals $(n=138)$ was included. As shown in Figure $5 a$, animals learn to respond to the odor independent of the kind of treatment. There is no difference between the three groups $(p>$ 0.8 ; df $=2 ; H=0.38$; Kruskal-Wallis test), demonstrating that a slight downregulation of PKA activity is not able to significantly affect acquisition of olfactory memory.

One group of trained bees was tested cumulatively 3, 6, and 24 hr after training for memory retention. A multiple-group comparison between the antisense S-ODN-treated group $(n=70)$, the scrambled S-ODN-treated group $(n=67)$, and the solventtreated group $(n=65)$ reveals a significant difference $(p<0.05$; df $=2 ; H=8.22$; Kruskal-Wallis test). The difference occurs because of a reduction in memory retention in the antisense S-ODN-treated group, because pairwise comparisons reveal a difference between the antisense S-ODN-treated group and the scrambled S-ODN-treated group $(p<0.05$; df $=1 ; U=1863.5$; Mann-Whitney $U$ test) and between the antisense S-ODNtreated group and the solvent-treated group $(p<0.05$; df $=1$; $U=1700.5$; Mann-Whitney $U$ test). No difference occurs between the scrambled S-ODN-injected group and the solventinjected group ( $p>0.6$; df $=1 ; U=2067$; Man-Whitney $U$ test), 


\begin{tabular}{|c|c|c|c|c|c|}
\hline $\begin{array}{l}\text { Timepoint after } \\
\text { injection }\end{array}$ & Untreated & $\begin{array}{l}\text { Antisense } \\
\text { S-ODN-injected }\end{array}$ & $\begin{array}{l}\text { Scrambled } \\
\text { S-ODN-injected }\end{array}$ & Solvent-injected & $\begin{array}{l}\text { Statistics (Kruskal-Wallis } \\
\text { test) }\end{array}$ \\
\hline \multicolumn{6}{|l|}{ PKA C subunit } \\
\hline $3 \mathrm{hr}$ & $1 \pm 0.02(34)$ & $0.98 \pm 0.02(34)$ & $1.01 \pm 0.02(37)$ & $0.98 \pm 0.02(34)$ & $p>0.4 ; H=2.45 ; \mathrm{df}=3$ \\
\hline $6 \mathrm{hr}$ & $1 \pm 0.02(29)$ & $0.85 \pm 0.03(32)$ & $0.97 \pm 0.03(31)$ & $0.95 \pm 0.03(31)$ & $p<0.05 ; H=13.47 ; \mathrm{df}=3$ \\
\hline $24 \mathrm{hr}$ & $1 \pm 0.02(30)$ & $1.07 \pm 0.03(30)$ & $1.03 \pm 0.02(30)$ & $1.06 \pm 0.02(31)$ & $p>0.3 ; H=3.59 ; \mathrm{df}=3$ \\
\hline \multicolumn{6}{|c|}{ PKA R subunit type II } \\
\hline $3 \mathrm{hr}$ & $1 \pm 0.03(34)$ & $0.97 \pm 0.03(35)$ & $0.98 \pm 0.04(35)$ & $1.01 \pm 0.03(34)$ & $p>0.9 ; H=5.43 ; \mathrm{df}=3$ \\
\hline $6 \mathrm{hr}$ & $1 \pm 0.03(31)$ & $0.95 \pm 0.04$ & $0.98 \pm 0.03(31)$ & $0.98 \pm 0.03(31)$ & $p>0.3 ; H=3.00 ; \mathrm{df}=3$ \\
\hline $24 \mathrm{hr}$ & $1 \pm 0.03(31)$ & $1.07 \pm 0.06(32)$ & $1.08 \pm 0.03(32)$ & $1.02 \pm 0.03(31)$ & $p>0.3 ; H=3.34 ; \mathrm{df}=3$ \\
\hline \multicolumn{6}{|l|}{ PKC } \\
\hline $3 \mathrm{hr}$ & $1 \pm 0.03(27)$ & $0.96 \pm 0.05(28)$ & $1.03 \pm 0.06(27)$ & $1.08 \pm 0.06(28)$ & $p>0.4 ; H=2.75 ; \mathrm{df}=3$ \\
\hline $6 \mathrm{hr}$ & $1 \pm 0.03$ & $0.93 \pm 0.04(32)$ & $0.96 \pm 0.05(32)$ & $0.96 \pm 0.03(32)$ & $p>0.4 ; H=2.49 ; \mathrm{df}=3$ \\
\hline $24 \mathrm{hr}$ & $1 \pm 0.04(29)$ & $1.07 \pm 0.07(29)$ & $1.00 \pm 0.04(29)$ & $1.04 \pm 0.06(24)$ & $p>0.9 ; H=0.49 ; \mathrm{df}=3$ \\
\hline
\end{tabular}

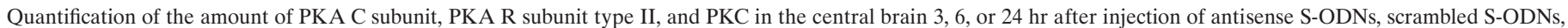

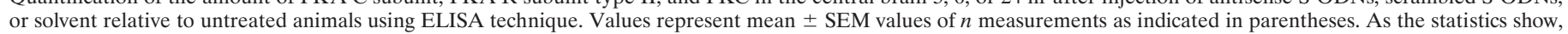

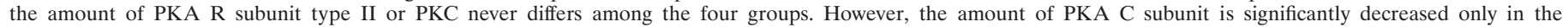
antisense-treated group only at $6 \mathrm{hr}$ after injection.

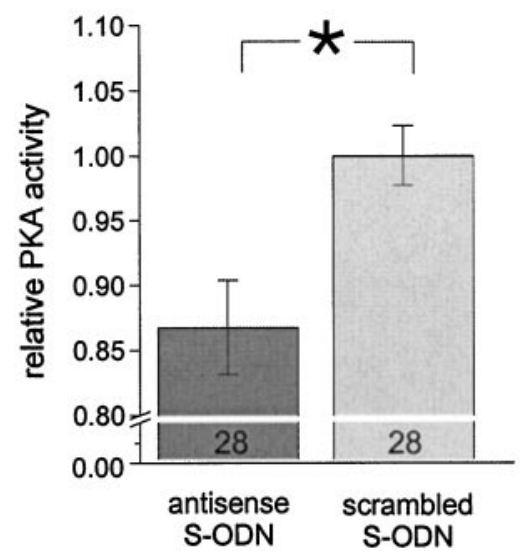

Figure 4. Quantification of PKA activity in central brains $6 \mathrm{hr}$ after injection of antisense S-ODNs or scrambled S-ODNs. ${ }^{32} \mathrm{P}$ incorporation into phosphatase inhibitor I in the presence of $5 \mu \mathrm{M} 8$-Br-cAMP was quantified. For each experiment, values were normalized to the mean value of the scrambled S-ODN-injected animals. The asterisk indicates a significant difference between the two groups $(p<0.05$; Mann-Whitney $U$ test).

demonstrating that the injection of nonspecific S-ODNs causes no detectable side effect on memory retention. Interestingly, daywise comparisons of the antisense-treated bees with the scrambled S-ODN-injected bees reveal no significant difference at $3(p>$ $0.4 ; \mathrm{df}=1 ; \chi^{2}=0.65 ; \chi^{2}$ test $)$ or $6\left(p>0.3 ; \mathrm{df}=1 ; \chi^{2}=0.76\right.$; $\chi^{2}$ test) $\mathrm{hr}$ after training. However, if tested $24 \mathrm{hr}$ after training, the antisense S-ODN-injected bees show a significant decrease in memory retention compared with scrambled S-ODN-injected animals $\left(p<0.05\right.$; df $=1 ; \chi^{2}=6.49 ; \chi^{2}$ test $)$.

To investigate whether the amnestic effect of a reduction in PKA C subunit was sustained or transiently restricted to a specific memory phase, a second group of bees was cumulatively tested 1-4 d after training. As Figure $5 c$ shows, the lower probability of antisense S-ODN-treated bees to respond to the learned odor remains over $4 \mathrm{~d}$. A multiple-group comparison between the antisense S-ODN-treated group $(n=77)$, the scrambled S-ODNtreated group $(n=66)$, and the solvent-injected group $(n=73)$ reveals a significant difference $(p<0.05$; df $=2 ; H=28.42$;
Kruskal-Wallis test). Again, the antisense S-ODN-treated group is significantly different from the scrambled S-ODN-treated group ( $p<0.05 ; \mathrm{df}=1 ; U=1691$; Mann-Whitney $U$ test $)$ and the solvent-treated group ( $p<0.05$; df $=1$; $U=1441$; MannWhitney $U$ test). The scrambled S-ODN-treated group is not different from the solvent-treated group $(p>0.2$; df $=1 ; U=$ 2118; Mann-Whitney $U$ test), showing that nonspecific S-ODNs do not cause long-term side effects on memory retention. Pairwise comparisons of the antisense-treated bees with the scrambled S-ODN-injected bees reveal a significant reduction in memory retention at day $1\left(p<0.05 ; \mathrm{df}=1 ; \chi^{2}=3.96 ; \chi^{2}\right.$ test $)$, day $2\left(p<0.05 ; \mathrm{df}=1 ; \chi^{2}=5.56 ; \chi^{2}\right.$ test $)$, day $3(p<0.05 ; \mathrm{df}=1$; $\chi^{2}=14.84 ; \chi^{2}$ test $)$, and day $4\left(p<0.05 ; \mathrm{df}=1 ; \chi^{2}=4.28 ; \chi^{2}\right.$ test) after training.

\section{Downregulation of the amount of PKA C subunit $3 \mathrm{hr}$ after training causes no effect on learning and memory}

After having shown that downregulation of PKA $\mathrm{C}$ subunit during training impairs long-term memory $24 \mathrm{hr}$ later, we took advantage of the delayed and reversible effect of antisense S-ODNs to pose the question whether a downregulation $3 \mathrm{hr}$ later is still able to impair long-term memory. Bees were injected $3 \mathrm{hr}$ before training, which, as a conclusion of the experiment shown in Figure 3, causes a downregulation of PKA C subunit $\sim 3 \mathrm{hr}$ after training. The bees were tested for memory retention equivalent to the experiments described above. As Figure $6 a$ shows, acquisition is not affected by the treatment with antisense or scrambled S-ODNs compared with solvent injection. There is no significant difference between antisense S-ODN-injected ( $n=120)$, scrambled S-ODN-injected $(n=123)$, and solvent-injected $(n=124)$ bees $(p>0.1$; df $=2 ; H=3.87$; Kruskal-Wallis test). When tested 3, 6, and $24 \mathrm{hr}$ after training (Fig. 6b), there is, unlike the bees injected $6 \mathrm{hr}$ before training, no difference between the three tested groups [antisense S-ODN-injected $(n=63)$, scrambled S-ODN-injected $(n=62)$, or solvent-injected $(n=61)$ bees] is detectable ( $p>0.8$; df $=2 ; H=0.43$; Kruskal-Wallis test). Similarly, no difference occurs at days $1-4$ after training $(p>0.3$; df $=2 ; H=1.98$; Kruskal-Wallis test) (Fig. $6 c$ ) between antisense S-ODN-injected $(n=57)$, scrambled S-ODN-injected $(n=$ $61)$ and solvent-injected $(n=63)$ bees, demonstrating that a slight 

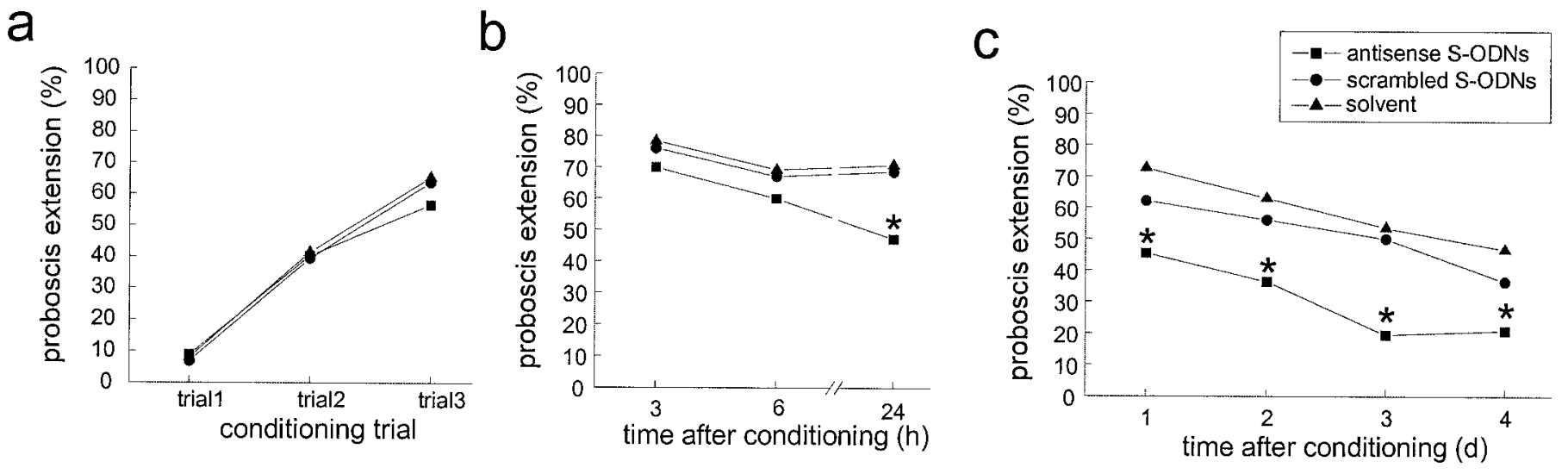

Figure 5. Reduction of PKA activity during conditioning affects long-term memory retention. Six hours after injection of antisense S-ODNs (-m-), scrambled S-ODNs (-0-), or solvent (-⿳亠幺-), bees were trained with three conditioning trials. There is no difference between the three tested groups in acquisition $(a)$. When tested 3, 6, or $24 \mathrm{hr}$ after conditioning $(b)$, the antisense-treated bees show reduced memory retention only $24 \mathrm{hr}$ after the training procedure. This effect is sustained, because memory retention stays impaired over 1-4 $\mathrm{d}$ after conditioning $(c)$. Statistics are as explained in Results.

reduction in PKA with an onset in the range of $3 \mathrm{hr}$ after learning is unable to cause any specific memory impairment.

\section{DISCUSSION}

In this study, we have investigated the role of PKA in associative learning and memory in the honeybee. As a new approach in insects, short S-ODNs with an antisense sequence complementary to a PKA C subunit were injected into the brain to decrease the amount of $\mathrm{C}$ subunit and thereby affect PKA activity. In vertebrates, the use of antisense oligodeoxynucleotides to unravel molecular bases of behavior is well established (for review, see Ogawa and Pfaff ,1998). Concerning research on learning and memory, a variety of proteins has been investigated in several vertebrate species using antisense oligodeoxynucleotides (Mileusnic et al., 1996; Guzowski and McGaugh, 1997; Lamprecht et al., 1997; Wu et al., 1997; Meiri et al., 1998). As a general evaluation, the honeybee brain provides an appropriate system for the application of antisense S-ODNs. Bee neurons take up labeled S-ODNs, which are detectable in somata in the range of hours after injection (Fig. 1), as has also been demonstrated for rats (Yee et al., 1994) and mice (Ogawa et al., 1995). In the bee, it is advantageous that the volume of injected fluid can be huge (200 nl) compared with the total brain volume of $\sim 1 \mu$ l because of the rather voluminous median ocellar tract. Diffusion paths are therefore short, and large brain parts can be affected. No toxic side effects produced by the injection of S-ODNs were observed at the described concentrations. Independent from the sequence, the survival rate of S-ODN-treated bees was indistinguishable from that of untreated or solvent-injected bees. Neither the ability to perform the proboscis extension reflex nor the ability to learn, and therefore to smell the carnation odor, was affected by antisense or scrambled S-ODN treatment. A further advantage (compared with a vertebrate) is the relatively high sample size possible with bees, which allows, in combination with sensitive detection methods, the determining of rather small decreases (10-15\%) in the amount and activity of the target protein, the PKA C subunit. (Figs. 3, 4). The PKA C subunit provides an advantageous precursor molecule for the establishing of the antisense approach because PKA-blocking cAMP analogs, such as adenosin $3^{\prime}, 5^{\prime}$ cyclic-monophosphothioate, Rp-isomer (Rp-cAMPS), can be used to control the behavioral effects caused by antisense oligo- a

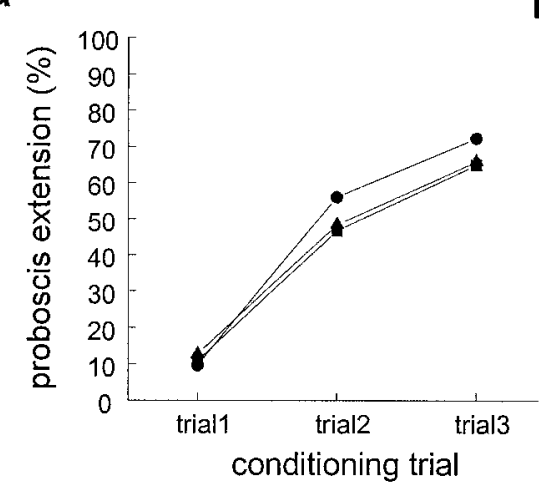

b

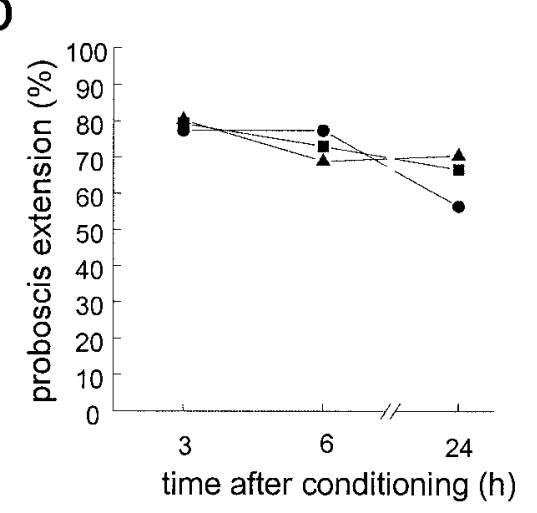

C

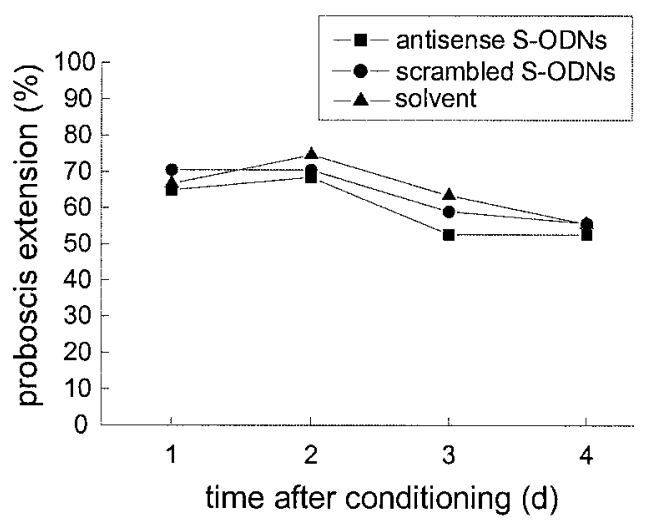

Figure 6. Reduction of PKA activity after conditioning affects neither acquisition nor memory retention. Three hours after injection of antisense S-ODNs (- - ), scrambled S-ODNs (-0-), or solvent $(-\mathbf{-}-)$, bees were trained with three conditioning trials. There is no significant difference between the three tested groups in acquisition $(a)$. When tested 3,6 , or $24 \mathrm{hr}$ after conditioning $(b)$, no difference occurs between the three tested groups. When tested 1-4 d after conditioning, likewise no difference is detectable between the three groups. Statistics are as explained in Results. 
nucleotides. First experiments using PKA-blocking Rp-cAMPS during the learning period lead to comparable memory deficits $1 \mathrm{~d}$ after training (U. Müller, unpublished observations).

Recently, several genes from the honeybee that are possibly involved in neuronal processes have been cloned and sequenced (Blenau et al., 1998; Eisenhardt et al., 1998; Humphries and Ebert, 1998; Kamikouchi et al., 1998). The antisense approach could, therefore, be promising for the future. However, the halflife of PKA in the bee is not known, making it impossible to determine how effective antisense S-ODNs block the de novo synthesis of PKA. Because the turnover rate is critical for the effectiveness of the method, its use with other target proteins might require adapting the application time for each case individually. Multiple or continuous injections might help to enhance the target protein-decreasing effect.

Using a specific antisense sequence, only one isoform of PKA $\mathrm{C}$ subunit from an unknown number is affected. In Drosophila, for example, two isoforms, DC0 and DC2, have been shown to exert PKA activity (Foster et al., 1988; Kalderon and Rubin, 1988; Skoulakis et al., 1993; Meléndez et al., 1995). However, it has been suggested that the isoform $\mathrm{DC} 0$, the homolog to the bee PKA C subunit on which we based our work, takes by far the majority of PKA activity in the fly brain (Lane and Kalderon, 1993; Davis et al., 1995). Because of the high degree of sequence homology $(>90 \%)$ between $\mathrm{DC} 0$ and the corresponding bee protein (Rosenboom et al., 1996), an anti-DC0 antibody specifically recognizes PKA C subunit in the bee (Fig. $2 a$ ) and could be used in this work. The mushroom bodies reveal a stronger immunostaining of PKA C subunit compared with antennal lobes or the protocerebrum (Fig. 2c). This correlates to investigations on Drosophila in which a preferential expression of DC0 in mushroom bodies has also been described (Skoulakis et al., 1993). In the honeybee, quantifications of PKA R subunit (type II) concentrations and of PKA activity also reveal a higher concentration of PKA in the central brain parts containing the mushroom bodies (Müller, 1997) compared with antennal lobes or optical lobes. Thus, the PKA-decreasing effect of antisense S-ODNs might be most pronounced in this neuropil, which is often connected with learning and memory in the honeybee and in Drosophila (Davis, 1993; Menzel et al., 1994). However, it cannot be excluded that other neuropils affected by S-ODN treatment significantly contribute to the behavioral effects, e.g., the antennal lobes, which are also involved in olfactory learning (Hammer and Menzel, 1998; Faber et al., 1999) and reveal PKA activity inducible by the US (Hildebrandt and Müller, 1995a).

Compared with other approaches, such as mutants or transgenics, the antisense method offers the advantage of reversibility. That allowed us to ask not only which parts of the memory trace could be impaired by a reduction in PKA activity, but also at what time period PKA activity must be reduced to cause any impairment. Our experiments clearly demonstrate the dependence of a long-term memory $24 \mathrm{hr}$ after training on the intact PKA activity around the training period (Figs. 5, 6), showing that PKA is involved in the memory-inducing machinery. Because we have no evidence for a change in the amount of PKA after training and because memory retention $1 \mathrm{~d}$ after training is independent from protein synthesis (Wittstock et al., 1993; Wüstenberg et al., 1998), the memory impairment must be caused by a decrease in PKA activity during the learning period and not by a block of a putative training-induced synthesis of PKA. The observation that olfactory conditioning causes a transient PKA activation during CS-US pairing (Eisenhardt et al., 1997; Grünbaum and Müller,
1997) supports the idea that PKA exerts its memory-inducing effects during learning. However, our findings reported here do not rule out a possible role of PKA for acquisition or shorter-term memory phases in the range of 3 to $6 \mathrm{hr}$ after training. First, the degree of reduction in PKA activity (10-15\%) might be insufficient to impair acquisition or shorter-term memory. Second, other forms of memory may run in parallel and dominate retention during the 3-6 hr period. Third, the localization of the effects of antisense S-ODNs might be restricted to brain regions not involved in acquisition or short-term plasticity. These three points could explain why our results do not fit the memory phases impaired in transgenic Drosophila flies. Flies expressing a heatshock induced PKA inhibitor peptide or fragments of PKA R subunit or $\mathrm{C}$ subunit throughout the whole animal reveal impairments of memory $4 \mathrm{hr}$ after training (Drain et al., 1991). Flies with a mutated PKA $C$ subunit that reveal much higher reductions in cAMP-stimulated PKA activity $(>80 \%)$ have defects in initial learning and memory in the range of hours after training (Skoulakis et al., 1993; Li et al., 1996), whereas flies revealing less severe reductions in PKA activity show only mild impairments in learning (Skoulakis et al., 1993). However, tests on long-term memory have not been reported using these mutants. Differences in the described memory phase affected by impairments of the PKA pathway between our report and those from Drosophila could also rely on different learning paradigms, aversive conditioning in Drosophila versus rewarding conditioning in the bee, or could simply be species-dependent.

However, the dissection of a long-term memory phase dependent on PKA has striking parallels in vertebrates. A late phase of LTP in the hippocampus, a cellular model for synaptic processes underlying specific forms of learning and memory, has been shown to be dependent on PKA (Frey et al., 1993; Matthies and Reymann, 1993; Huang and Kandel, 1994; Nguyen and Kandel, 1996). A transgenic mouse carrying a regulatory subunit with mutated cAMP binding sites, which therefore acts as a PKA inhibitor, reveals both impairments in a late phase of LTP and in the consolidation of a long-term memory. Interestingly, the shortterm memory is unaffected (Abel et al., 1997). Pharmacological approaches in rats also demonstrate a role of PKA in long-term memory (Bernabeu et al., 1997).

In the honeybee, molecular pathways mediating olfactory learning and memory upstream of PKA are partially known. A putative octopaminergic neuron mediates the reward information of the US (Hammer, 1993). Octopamine injected into the antennal lobe or the mushroom body is able to substitute for the US (Hammer and Menzel, 1998). Moreover, octopamine is able to activate PKA in the antennal lobes (Hildebrandt and Müller, 1995b) and in cultured Kenyon cells, the intrinsic cells of the mushroom bodies (Müller, 1997). However, molecular components downstream from PKA have not yet been identified. Evidence from Drosophila (Yin et al., 1994), Aplysia (Bartsch et al., 1995), and mouse (Bourtchuladze et al., 1994) reveal that a protein synthesis-dependent long-term memory is induced by phosphorylation of cAMP response element-binding protein, a transcription factor, and PKA target (for review, see Silva et al., 1998). However, in the bee, memory retention at $24 \mathrm{hr}$ after training is independent of transcription and translation (Wittstock et al., 1993; Wüstenberg et al., 1998). A protein synthesis dependence of memory retention is detectable no earlier than 3 d after training (Grünbaum and Müller, 1998; Wüstenberg et al., 1998). That means that, in the bee, PKA induces a longterm memory that appears earlier than the protein synthesis- 
dependent long-term memory. Interestingly, there is a striking correlation between the PKA-dependent long-term memory and the dependence of a three-trial induced long-term memory $24 \mathrm{hr}$ after conditioning on nitric oxide synthase (Müller, 1996). In the future, it will be interesting to clarify the concerted action of the molecular pathways involved in memory formation in the bee, a task for which the antisense approach could be a helpful tool.

\section{REFERENCES}

Abel T, Kandel ER (1998) Positive and negative regulatory mechanisms that mediate long-term memory storage. Brain Res Rev 26:360-378.

Abel T, Nguyen PV, Barad M, Deuel AS, Kandel ER, Bourtchouladze R (1997) Genetic demonstration of a role for PKA in the late phase of LTP and in hippocampus-based long-term memory. Cell 88:615-626.

Bartsch D, Ghirardi M, Skehel PA, Karl KA, Herder SP, Chen M, Bailey CH, Kandel ER (1995) Aplysia CREB2 represses long-term facilitation: relief of repression converts transient facilitation into long-term functional and structural change. Cell 83:979-992.

Bernabeu R, Bevilaqua L, Ardenghi P, Bromberg E, Schmitz P, Bianchin M, Izquierdo I, Medina JH (1997) Involvement of hippocampal cAMP/cAMP-dependent protein kinase signaling pathways in a late memory consolidation phase of aversively motivated rats. Proc Natl Acad Sci USA 94:7041-7046.

Bitterman ME, Menzel R, Fietz A, Schäfer S (1983) Classical olfactory conditioning of proboscis extension in honeybees (Apis mellifera). J Comp Physiol 97:107-119.

Blenau W, Erber J, Baumann A (1998) Characterization of a dopamine D1 receptor from Apis mellifera: cloning, functional expression, pharmacology, and mRNA localization in the brain. J Neurochem 70:15-23.

Bourtchuladze R, Frenguelli B, Blendy J, Cioffi D, Schutz G, Silva AJ (1994) Deficient long-term memory in mice with a targeted mutation of the cAMP-responsive element-binding protein. Cell 79:59-68.

Bradford MM (1976) A rapid and sensitive method for the quantitation of microgram quantities of protein utilizing the principle of protein-dye binding. Anal Biochem 72:248-254.

Byrne JH, Zwartjes R, Homayouni R, Critz S, Eskin A (1993) Roles of second messenger pathways in neuronal plasticity and in learning and memory: insights gained from Aplysia. In: Advances in second messenger and phosphoprotein research, Vol 27 (Nairn AC, Shenolikar S, eds), pp 47-108. New York: Raven.

Davis RL (1993) Mushroom bodies and Drosophila learning. Neuron 11:1-14.

Davis RL (1996) Physiology and biochemistry of Drosophila learning mutants. Physiol Rev 76:299-317.

Davis RL, Cherry J, Dauwalder B, Han PL, Skoulakis E (1995) The cyclic AMP system and Drosophila learning. Mol Cell Biochem 149-150:271-278.

Drain P, Folkers E, Quinn WG (1991) cAMP-dependent protein kinase and the disruption of learning in transgenic flies. Neuron 6:71-82.

Dubnau J, Tully T (1998) Gene discovery in Drosophila: new insights for learning and memory. Annu Rev Neurosci 21:407-444.

Eisenhardt D, Müller U, Kre $\beta$ H, Menzel R (1997) Induction of associative olfactory memory in the honeybee: prolonged PKA activation and CREB. Soc Neurosci Abstr 23:1336.

Eisenhardt D, Müller U, Kre $\beta$ H, Menzel R (1998) Cloning of CREB from the honeybee brain. Eur J Neurosci [Suppl 10] 10:261.

Faber T, Joerges J, Menzel R (1999) Associative learning modifies neural representations of odors in the insect brain. Nat Neurosci 2:74-78.

Foster JL, Higgins GC, Jackson FR (1988) Cloning, sequence, and expression of the Drosophila cAMP-dependent protein kinase catalytic subunit gene. J Biol Chem 263:1676-1681.

Frey U, Huang YY, Kandel ER (1993) Effects of cAMP simulate a late stage of LTP in hippocampal CA1 neurons. Science 260:1661-1664.

Grünbaum L, Müller U (1997) Associative olfactory learning induces distinct medium- and long-term changes in different second messenger pathways. Soc Neurosci Abstr 23:1339.

Grünbaum L, Müller U (1998) Induction of a specific olfactory memory leads to a long-lasting activation of protein kinase $\mathrm{C}$ in the antennal lobe of the honeybee. J Neurosci 18:4384-4392.

Guzowski JF, McGaugh JL (1997) Antisense oligodeoxynucleotidemediated disruption of hippocampal cAMP response element binding protein levels impairs consolidation of memory for water maze training. Proc Natl Acad Sci USA 18:2693-2698.
Hammer M (1993) An identified neuron mediates the unconditioned stimulus in associative olfactory learning in honeybees. Nature 366:59-63.

Hammer M (1997) The neural basis of associative reward learning in honeybees. Trends Neurosci 20:245-252.

Hammer M, Menzel R (1995) Learning and memory in the honeybee. J Neurosci 15:1617-1630.

Hammer M, Menzel R (1998) Multiple sites of associative odor learning as revealed by local brain microinjections of octopamine in honeybees. Learn Mem 5:146-156.

Hildebrandt H, Müller U (1995a) PKA activity in the antennal lobe of honeybees is regulated by chemosensory stimulation in vivo. Brain Res 679:281-288.

Hildebrandt H, Müller U (1995b) Octopamine mediates rapid stimulation of PKA in the antennal lobe of honeybees. J Neurobiol 27:44-50.

Huang YY, Kandel ER (1994) Recruitment of long-lasting and protein kinase A-dependent long-term potentiation in the CA1 region of hippocampus requires repeated tetanization. Learn Mem 1:74-82.

Humphries M, Ebert PR (1998) A dopamine receptor in honey bees that is expressed differentially between subtypes of intrinsic cells in the mushroom bodies. Soc Neurosci Abstr 24:1373.

Kalderon D, Rubin GM (1988) Isolation and characterization of Drosophila cAMP-dependent protein kinase genes. Genes Dev 2:1539-1556.

Kamikouchi A, Takeuchi H, Sawata M, Ohashi K, Natori S, Kubo T (1998) Preferential expression of the gene for a putative inositol 1,4,5triphosphate receptor homologue in the mushroom bodies of the brain of the worker honeybee Apis mellifera L. Biochem Biophys Res Commun 242:181-186.

Kuwabara M (1957) Bildung des bedingten Reflexes von Pavlovs Typus bei der Honigbiene, Apis mellifica. J Fac Sci Hokkaido Univ Ser VI Zool 13:458-464.

Lamprecht R, Hazvi S, Dudai Y (1997) cAMP response elementbinding protein in the amygdala is required for long- but not short-term conditioned taste aversion memory. J Neurosci 17:8443-8450.

Lane ME, Kalderon D (1993) Genetic investigation of cAMPdependent protein kinase function in Drosophila development. Genes Dev 7:1229-1243.

Li W, Tully T, Kalderon D (1996) Effects of a conditional Drosophila PKA mutant on olfactory learning and memory. Learn Mem 2:320-333.

Matthies H, Reymann KG (1993) Protein kinase A inhibitors prevent the maintenance of hippocampal long-term potentiation. NeuroReport 4:712-714.

Meiri N, Sun NK, Segal Z, Alkon DL (1998) Memory and long-term potentiation (LTP) dissociated: normal spatial memory despite CA1 LTP elimination with Kv1.4 antisense. Proc Natl Acad Sci USA 25:15037-15042.

Meléndez A, Li W, Kalderon D (1995) Activity, expression and function of a second Drosophila protein kinase A catalytic subunit gene. Genetics 141:1507-1520.

Menzel R, Müller U (1996) Learning and memory in honeybees: from behavior to neural substrates. Annu Rev Neurosci 19:379-404.

Menzel R, Durst C, Erber J, Eichmüller S, Hammer M, Hildebrandt H, Mauelshagen J, Müller U, Rosenboom H, Rybak J, Schäfer S, Scheidler A (1994) The mushroom bodies in the honeybee: from molecules to behaviour. In: Neural basis of behavioural adaptations. Fortschritte der Zoologie, Vol 39 (Schildberger K, Elsner N, eds) pp 81-102. Stuttgart, Germany: Fischer.

Mileusnic R, Anokhin K, Rose SP (1996) Antisense oligodeoxynucleotides to c-fos are amnestic for passive avoidance in the chick. NeuroReport 17:1269-1272.

Milner B, Squire LR, Kandel ER (1998) Cognitive neuroscience and the study of memory. Neuron 20:445-468.

Müller U (1996) Inhibition of nitric oxide synthase impairs a distinct form of long-term memory in the honeybee, Apis mellifera. Neuron 16:541-549.

Müller U (1997) Neuronal cAMP-dependent protein kinase type II is concentrated in mushroom bodies of Drosophila melanogaster and the honeybee Apis mellifera. J Neurobiol 33:33-44.

Nguyen PV, Kandel ER (1996) A macromolecular synthesis-dependent late phase of long-term potentiation requiring cAMP in the medial perforant pathway of rat hippocampal slices. J Neurosci 16:3189-3198.

Ogawa S, Pfaff DW (1998) Current status of antisense DNA methods in behavioral studies. Chem Senses 23:249-255. 
Ogawa S, Brown HE, Okano HJ, Pfaff DW (1995) Cellular uptake of intracerebrally administered oligodeoxynucleotides in mouse brain. Regul Pept 59:143-149.

Rosenboom H, Braun P, Müller U (1996) Molecular cloning of a DC0 like catalytic subunit of the protein kinase A from honeybee neuronal tissue. Soc Neurosci Abstr 22:697.

Silva AJ, Kogan JH, Frankland PW, Kida S (1998) CREB and memory. Annu Rev Neurosci 21:127-148.

Skoulakis EMC, Kalderon D, Davis RL (1993) Preferential expression in mushroom bodies of the catalytic subunit of protein kinase A and its role in learning and memory. Neuron 11:197-208.

Taylor SS, Buechler JA, Yonemoto W (1990) cAMP-dependent protein kinase: framework for a diverse family of regulatory enzymes. Annu Rev Biochem 59:971-1005.

Walaas SI, Greengard P (1991) Protein phosphorylation and neuronal function. Pharmacol Rev 43:299-349.
Wittstock S, Kaatz HH, Menzel R (1993) Inhibition of brain protein synthesis by cycloheximid does not affect formation of long-term memory in honeybees after olfactory conditioning. J Neurosci 13:1379-1386.

Wu HC, Chen KY, Lee WY, Lee EHY (1997) Antisense oligonucleotides to corticotropin-releasing factor impair memory retention and increase exploration in rats. Neuroscience 78:147-153.

Wüstenberg D, Gerber B, Menzel R (1998) Long- but not medium-term retention of olfactory memories in honeybees is impaired by actinomycin D and anisomycin. Eur J Neurosci 10:2742-2745.

Yee F, Ericson H, Reis DJ, Wahlestedt C (1994) Cellular uptake of intracerebroventricularly administered biotin- or digoxigenin-labeled antisense oligodeoxynucleotides in the rat. Cell Mol Neurobiol 14:475-486.

Yin JC, Wallach JS, Del Vecchio M, Wilder EL, Zhou H, Quinn WG, Tully $T$ (1994) Induction of a dominant negative CREB transgene specifically blocks long-term memory in Drosophila. Cell 79:49-58. 